\title{
Early Neonatal Outcome in Caesarean Section: A Developing Country Perspective
}

\author{
Bharat Choudhary, ${ }^{1, *}$ Yachana Choudhary, ${ }^{2}$ Abhijit P Pakhare, ${ }^{3}$ Deonath Mahto, ${ }^{4}$ and Latha
}

\section{Chaturvedula ${ }^{5}$}

${ }^{1}$ Department of Pediatrics, All India Institute of Medical Sciences, Bhopal, MP, India

${ }^{2}$ Department of Community Medicine, Gandhi Medical College, Bhopal, MP, India

${ }^{3}$ Department of Community and Family Medicine, All India Institute of Medical Sciences, Bhopal, MP, India

${ }^{4}$ Department of Pediatrics, Lady Harding Medical College, New Delhi, India

${ }^{5}$ Department of Obstetrics and Gynaecology, Jawaharlal Institute of Postgraduate Medical Education and Research Puducherry, India

"Corresponding author: Bharat Choudhary, Department of Pediatrics, All India Institute of Medical Sciences, Saket Nagar, MP 462024, Bhopal, India. Tel: +91-7024152855, E-mail: drbharatpaeder@gmail.com

Received 2016 July 20; Revised 2016 August 11; Accepted 2016 September 15.

\begin{abstract}
Objectives: To find out the early neonatal outcome (morbidity and early neonatal mortality) of the babies born by caesarean section (CS) and to compare the outcomes between elective and emergency CS.

Methods: A longitudinal study was conducted in a tertiary care hospital. Maternal and neonatal characteristics were noted.

Results: A total of 750 neonates were enrolled and $37 \%$ were born by elective CS. Out of 750 children $55 \%$ were male newborns and $45 \%$ were females. The NICU (neonatal intensive care unit) admission requirement was $24 \%$, whereas $3.33 \%$ of neonates died within 7 days of life. Neonatal morbidity was higher in emergency CS, similar to respiratory depression at birth (OR: 6.00, 95\% CI 3.06-11.78, $\mathrm{P}<0.001$ ), respiratory distress (OR: 4.6, 95\% CI 2.74 -7.82, P < 0.001) and requirement of resuscitation (OR: 5.54, 95\% CI 2.98 -10.32, P $<0.001$ ). Factors such as emergency CS [adj OR: 13.35(1.69-105.38), $\mathrm{P}=0.014$ ], prematurity [adj OR: 10.08 (3.33 -30.47), $\mathrm{P}<0.001$ ] and Apgar score $<7$ at 10 minutes [adj OR: 79.56 (16.63 - 381.50), P $<0.001$ ] were independently associated with NICU admissions and neonatal mortality.

Conclusions: Newborns delivered through emergency CS had a higher morbidity and mortality rate compared to elective CS. Adequate antenatal care and early referral may convert this emergency CS to normal or elective CS and can reduce neonatal morbidity and mortality.
\end{abstract}

Keywords: Elective Caesarean Section, Emergency Caesarean Section, Neonatal Outcome

\section{Introduction}

The early neonatal period is defined as the period from birth to seven days of life (1). Early neonatal outcome depends on various factors amongst which the mode of delivery is one of the important determinants of neonatal outcome. Thoughtful changes have occurred during the past three decades regarding the mode of delivery and perinatal outcome, including a recent increase in number of institutional deliveries, increased rates of cesarean sections (CS) and at the same time attempting to integrate woman's obstetric preferences.

In the past 20 years, there has been an increase in the rate of CS in developed as well as developing countries (2, 3). Overall the increasing rates of CS have created much research and debate in the medical literature. The increase in rates of cesarean delivery at an institutional level is not associated with any clear overall benefit for the baby or mother but is linked with increased morbidity to both (4). We conducted this study due to the paucity of Indian liter- ature on neonatal outcome in CS.

\section{Methods}

\subsection{Design and Study Population}

This was a longitudinal study carried out in the tertiary care institute in Southern India, between the periods of Jan 2009 - May 2009. Study protocol was approved by the human ethics committee of institute. Requirement of admission to NICU was considered as an adverse outcome on which sample size calculations were based. The estimated NICU admission rate of $25 \%$ with a $95 \%$ Confidence Interval of 21 to $29 \%$ required sample size was 468 by simple random sampling. However we decided to enroll consecutive newborns in a fixed study period and therefore adjusted the sample size by a 1.5 factor. Considering a non response rate of $5 \%$ the final required sample size was 738 . We have enrolled all consecutive newborns delivered by CS at our institute during the months of January 2009 to May 
2009. Informed consent was taken from the parents of the neonates in the language they were familiar with. Newborns whose delivery took place outside the institution as well as babies whose parents refused to give consent for their enrolment were not included.

\subsection{Variables}

Maternal characteristics such as age, parity, any medical illness, gestational age, presentation, indications for CS and type of CS were considered, whereas from the newborns aspect maturity, respiratory depression at birth, respiratory distress at birth, Apgar score, requirement of resuscitation, NICU admission, duration of NICU stay, requirement of ventilation, death within 7 days of birth and its underlying reasons were included.

\subsection{Definitions}

CS was considered to be elective if it was scheduled before the onset of labour and as emergency if scheduledduring or after the start of labour. Indications for caesarean section were divided into absolute and relative indications. The absolute indications included pelvic disproportion, chorioamnionitis, maternal pelvic deformity, eclampsia, fetal asphyxia, umbilical cord prolapse, placenta previa, abnormal lie and uterine rupture. Whereas pathological cardiotocograpy, failure to progress in labour and previous cesarean section were considered as relative indication. Cesarean sections on maternal requests were not included. Maturity was assessed by history (gestational age by 1st day of last menstrual period) and using the New Ballard Score (5). Respiratory depression was noted when there was a delay in initiating and maintaining respiration immediately after birth. Neonate was labelled as having birth asphyxia if the baby had two or more of the following criterias: a) $\mathrm{pH}<7.0$ in cord blood, b) Apgar score at $5 \mathrm{~min}$ utess $<3$ and c) clinical evidence of neonatal neurological sequel or multiorgan dysfunction (6). Early neonatal death was considered if the death of the neonate occurred within 7 days of birth.

\subsection{Statistical Analysis}

Statistical analysis was done using the IBM SPSS version 21. We used count and proportion to summarize nominal variables and mean and standard deviation to summarize numerical variables. Data collected for above parameters were described in the form of their frequency of occurrence in the emergency as well as the elective section group. For comparison of the mean scores of the above mentioned parameters in both groups, students ' $\mathrm{t}$ ' - independent test was used. To find out the association between two characteristics the Chi-square test was used and whenever a cell frequency was less than five the Fisher's exact test was used. Multinominal regression analysis was carried out by assumption that the NICU admission and early neonatal death depends on maternal, fetal parameters and mode of delivery. The overall goodness of fit was assessed by the Hosmer and Lemeshow test. The significance of individual coefficient was assessed by the Wald statistics. For each coefficient odds ratio and its confidence, a limit was computed. For all the tests a level of significance was taken as $\mathrm{P}<0.05$.

\section{Results}

A total of 750 neonates born by CS during the study period were included and out of the 750,269 (37.20\%, 95\% CI 33.75 -40.78) were elective sections and 471 (62.8\%, 95\%CI 59.22-66.25\%) were emergency sections.

\subsection{Maternal Characteristics}

A majority of the mothers were in the age group of 21 - 30 years in both groups, but a proportion of the mothers with the age of $<20$ years were higher in emergency section. In the elective section, most of the mothers were of second parity (59\%) and the majority (57\%) of mothers who underwent emergency section were primi. Major (33\%) indications for CS were previous section, fetal distress (39\%), breech presentation (15\%), cephalo-pelvic disproportion and pregnancy induced hypertension (6\%).

\subsection{Neonatal Parameters}

Table 1 depicts characteristics of newborns delivered by emergency and elective cesarean sections. Out of the 750 newborns, 415 (55.3\%) were male and 335 (44.7\%) were female. Overall the NICU admission requirement rate was $24 \%$ ( $95 \%$ CI of $21.14 \%$ to $27.39 \%$ ). Other neonatal characteristics are depicted in Table 1 . The mean birth weight of the babies was $2793 \pm 543.4$ gms (95\% CI 2729-2856 gms) and $2769 \pm 561.5$ gms (95\% CI 2769 -2819 gms) in elective and emergency sections respectively and the difference was not significant $(\mathrm{P}=0.492$, 95\% CI -112.25 to 54.59$)$. The average maturity in elective sections and emergency sections was $38 \pm 1.35$ weeks and $37 \pm 1.63$ weeks, with no significant difference between the two groups $(\mathrm{P}=0.063,95 \% \mathrm{CI}-0.444$ to 0.012 ).

\subsection{Neonatal Morbidity}

The mean Apgar score at 1, 5 and 10 minutes were significantly higher in the elective section compared to the emergency section and they were 7.85 and 7.03 (0.825,95\% CI 0.569-1.081, P < 0.0001), 8.95 and 8.96 ( 0.596, 95\% CI 
Table 1. Characteristics of Newborns Delivered by Cesarean Section

\begin{tabular}{|c|c|c|c|c|c|}
\hline Factors & & All Sections, No. (\%) & Elective Sections, No. (\%) & $\begin{array}{c}\text { Emergency Sections, No. } \\
(\%)\end{array}$ & $\mathbf{P}$ \\
\hline \multirow{2}{*}{ Mortality } & Yes & $25(3.3)$ & $1(0.4)$ & $24(5.1)$ & \multirow{2}{*}{$<0.001$} \\
\hline & No & $725(96.7)$ & $278(99.6)$ & $447(94.9)$ & \\
\hline \multirow{2}{*}{ NICU admission } & Present & $181(24)$ & $32(11)$ & $149(32)$ & \multirow{2}{*}{$<0.001$} \\
\hline & Absent & $569(76)$ & $247(89)$ & $322(68)$ & \\
\hline \multirow{2}{*}{ Hospital stay, (days) } & $<3$ & $652(87)$ & $267(96)$ & $385(82)$ & \multirow{2}{*}{$<0.001$} \\
\hline & $>3$ & $98(13)$ & $12(4)$ & $86(18)$ & \\
\hline \multirow{2}{*}{ Need For Ventilation } & Yes & $32(4)$ & $2(1)$ & $30(6)$ & \multirow{2}{*}{$<0.001$} \\
\hline & No & $318(96)$ & $277(99)$ & $441(94)$ & \\
\hline \multirow{2}{*}{ Resuscitation } & Yes & $106(14)$ & $12(5)$ & $94(20)$ & \multirow{2}{*}{$<0.001$} \\
\hline & No & $644(86)$ & $267(95)$ & $377(80)$ & \\
\hline \multirow{2}{*}{ Apgar score @ 10 min } & $<7$ & $17(2)$ & $1(0.3)$ & $16(3.4)$ & \multirow{2}{*}{0.007} \\
\hline & $\geq 7$ & $733(98)$ & $278(99.7)$ & $455(96.6)$ & \\
\hline \multirow{2}{*}{ Maturity,(weeks) } & $<37$ & $95(13)$ & $23(8)$ & $72(15)$ & \multirow{2}{*}{0.005} \\
\hline & $>37$ & $655(87)$ & $256(92)$ & $399(85)$ & \\
\hline \multirow{2}{*}{ Birth Weight, (grams) } & $<2500$ & $14(2)$ & $5(2)$ & $9(2)$ & \multirow{2}{*}{0.908} \\
\hline & $\geq 2500$ & $736(98)$ & $274(98)$ & $462(98)$ & \\
\hline \multirow{2}{*}{ Respiratory depression at birth } & Present & $96(13)$ & $10(4)$ & $86(18)$ & \multirow{2}{*}{$<0.001$} \\
\hline & Absent & $654(87)$ & $269(96)$ & $385(81)$ & \\
\hline \multirow{2}{*}{ Requirement of resuscitation } & Present & $106(14)$ & $12(5)$ & $94(20)$ & \multirow{2}{*}{$<0.001$} \\
\hline & Absent & $644(86)$ & $267(95)$ & $377(80)$ & \\
\hline \multirow{2}{*}{ Respiratory distress at birth } & Present & $132(18)$ & $18(7)$ & $114(24)$ & \multirow{2}{*}{0.001} \\
\hline & Absent & $618(82)$ & $261(93)$ & $357(76)$ & \\
\hline \multirow{2}{*}{ Birth Trauma } & Present & $31(4)$ & $3(1)$ & $28(6)$ & \multirow{2}{*}{$<0.01$} \\
\hline & Absent & $719(96)$ & $276(99$ & $443(94)$ & \\
\hline
\end{tabular}

Abbreviation: NICU, neonatal intensive care unit.

$0.396-0.795, \mathrm{P}<0.0001), 9.07$ and 8.7 (0.298,95\% 0.129 $0.467, \mathrm{P}=0.001)$ respectively. It has also been noted that respiratory depression was present in $41 \%$ of the babies whose mother received opioids before section, whereas as only $10 \%$ of the babies had respiratory depression in the group where the mother did not receive any opioids (Table 1).

Twenty percent of babies born by emergency CS required initial resuscitation compared to $5 \%$ of babies born by elective section. In the later group, 53\% of babies who required resuscitation needed support with only bag and mask ventilation. However, in the former group $40 \%$ of the babies were resuscitated with more than one measure including bag and mask ventilation, tracheal suctioning and intubation. Entirely, 132 (18\%) babies had respiratory dis- tress at birth, $7 \%$ in the elective group and $24 \%$ in emergency section. Common causes of respiratory distress were TTN (transient tachypnea of new born) (83\%), MAS (meconium aspiration syndrome) (11\%) and RDS (respiratory distress syndrome) (6\%), whereas in the emergency group, TTN (53\%), MAS (40\%), congenital pneumonia (5\%) and RDS (2\%) accounted for respiratory distress. The mean duration of stay at the NICU was significantly higher in emergency section compared to the elective CS with the mean stay of 3.09 and 3.54 days (0.458, 95\% CI 0.248-0.668, $\mathrm{P}<0.0001$ ) (Table 1).

\subsection{Neonatal Mortality}

We observed a 3.33\% (95\% CI 2 - 4.6\%) mortality rate in babies delivered by CS, with the mortality rate in emergency section significantly higher than the emergency 
group (OR: 14.92, 95\% CI $2.00-110.95, \mathrm{P}=0.001)$. The most common causes of mortality were MAS (44\%), birth asphyxia (36\%), RDS (16\%) and sepsis (4\%). One baby succumbed in elective section group due to severe birth asphyxia (Table 1 ).

\subsection{Risk Factors for Neonatal Morbidity and Mortality}

On multinomial regression analysis with significant fitting of model-emergency CS [adj OR:2.55 (1.57 - 4.10), P < 0.001], prematurity [adj OR:5.11(3.00 - 8.86), P $\leq$ 0.001], babies born primi parous mothers [adj OR:1.50(1.00-2.25), $\mathrm{P}=$ 0.049] and Apgar score $<7$ at 10 minutes [adj OR: 5.52(1.29 23.60), $\mathrm{P}=0.02$ ] were independently associated with NICU admissions, and emergency CS [adj OR:13.35(1.69-105.38), P $=0.014$ ], prematurity [adj OR:10.08 (3.33 - 30.47), P $<0.001$ ] and Apgar score $<7$ at 10 minutes [adj OR: 79.56 (16.63 - 381.50), $\mathrm{P}<0.001$ ] were independently associated with neonatal mortality (Tables 2 and 3). However low birth weight, abnormal liquor amount and nonchephalic presentations were not found to be significant independent factors for the NICU admission and early neonatal morbidity.

\section{Discussion}

At our institution we had a CS rate of around $25 \%$, which was higher than the WHO recommendation of $15 \%$ (7). The reason for this is because of the very high referral rate of patients from peripheries. Many of these patients had multiple complications when coming to us. This also elucidates higher proportion of emergency CSs compared to the elective section. The most common indication for elective section was the previous section compared to the fetal distress in the emergency section, which was similar to the Liston et al. (8).

Though CS was supposed to improve maternal and neonatal morbidity, it is true only to a certain extent. A world wide based population ecological study showed that the maternal and perinatal outcome improves until the rate of the cesarean section is within $10 \%$ above these limits. The maternal and neonatal outcome did not improve, especially with reference to developing countries it worsened with rising CS rate above 10\% (9). However, the rates of CS are increasing rapidly and in India it ranges from 20$34 \%$ in different cities (10-12).

In the last decade, various efforts have been done to document the impact of CS on fetal outcomes in comparison to vaginal birth as well as verifing higher morbidity in babies born by elective CSs compared to vaginal birth, with special reference to respiratory morbidity. A study from Nova Scotia showed respiratory depression at birth,
Apgar score $<3$ and HIE were more common in emergency CS compared to elective and vaginal delivery (OR 4.6, 95\% CI3.7 - 5.1), whereas TTN and RDS were more common in elective CS compared to emergency section (OR: 2.08, 95\% CI-1.23 - 3.54) (8). In our study the frequency of respiratory distress (18\%) was much higher and more common in emergency CS compared to elective CS (OR: 4.6,95\% CI 2.74 - 7.82, $\mathrm{P}<0.001)$. This might be because of a higher proportion of high-risk mothers with fetal distress and their delayed referral in our cohort.

Another study compared elective sections at 38 and 39 weeks, which showed NICU admission rate of $13.9 \%$ and $11.9 \%$, we also had an NICU admission rate of $11 \%$ in the elective group (13). Jose Vilaar et al. found that there is a higher risk of neonatal mortality in emergency CS compared to elective section and vaginal delivery in neonates with cephalic presentations, whereas CS in breech presentation had a protective effect on mortality (4). In our study there was no significant difference between neonatal mortality in cephalic and non cephalic presentation [OR: 0.467 (0.164 - 1.323), $\mathrm{P}=0.152$ ]. They also documented that neonates born with CS had a longer stay compared to vaginal birth, and the proportion of children who stayed at the hospital $>7$ days were similar in elective [2.55\%, OR 2.54 , 95\% CI (2.01-3.20)] and intrapartum CS [2.18\%, OR 2.31, 95\%Cl $(1.72$ - 3.11)]. Similar results were presented in a WHO global health survey (14). Our data showed the mean in NICU stay was $3.55 \pm 2.20$ days in emergency CS and $3.09 \pm 0.56$ days in elective CS. This difference was significant $(0.458,95 \% \mathrm{CI}$ $0.248-0.668, \mathrm{P}<0.0001)$.

Another study from India with similar objectives but with different cohort also documented a higher rate of neonatal morbidity in the emergency group (15). In a retrospective study, Berlit et al. showed prematurity (OR 2.145, P $=0.024)$ and silent cardiotocography $(\mathrm{OR} 0.426, \mathrm{P}=0.038)$ as a major risk factor for adverse neonatal outcome in emergency CS (16). In our study emergency CS [adj OR: 2.55 (1.57 - 4.10), P< 0.001], prematurity [adj OR: 5.11(3.00 - 8.86), $\mathrm{P}<0.001$ ], babies born to premature mothers [adj OR: 1.50 (1.00 - 2.25), $\mathrm{P}=0.049$ ] and Apgar score $<7$ at 10 minutes [adj OR: 5.52 (1.29 - 23.60), P = 0.02] were independently associated with the NICU admissions and emergency CS [adj OR:13.35(1.69-105.38), $\mathrm{P}=0.014$.$] , prematurity [adj OR:10.08$ (3.33 - 30.47), $\mathrm{P}<0.001]$ and Apgar score $<7$ at 10 minutes [adj OR:79.56(16.63-381.50), P< 0.001] were independently associated with neonatal mortality. In a WHO global survey rate of elective as well as emergency CSs, they were independently associated with neonatal mortality (17).

There are limited studies available in literature on the neonatal outcome in CS, especially from developing countries. We tried to focus on the outcome of the neonates delivered by CS, which will help the preparation of their man- 
Table 2. Univariate Analysis for Neonatal NICU Admission and Early Neonatal Death in CS - Cesarean Section

\begin{tabular}{|c|c|c|c|c|c|c|}
\hline \multirow[t]{2}{*}{ Variables } & & \multicolumn{3}{|c|}{ Neonatal-Outcome } & \multirow[b]{2}{*}{$\begin{array}{c}\text { NICU Admission P, OR (95\% CI of } \\
\text { OR) }\end{array}$} & \multirow[b]{2}{*}{$\begin{array}{c}\text { Neonatal Death P, OR (95\% CI o } \\
\text { OR) }\end{array}$} \\
\hline & & $\begin{array}{l}\text { No Admission, No Death } \\
\text { Count Row, No. (\%) }\end{array}$ & $\begin{array}{l}\text { NICU Admission } \\
\text { Count Row, No. (\%) }\end{array}$ & $\begin{array}{l}\text { NICU Admission and Death } \\
\text { Count Row, No. (\%) }\end{array}$ & & \\
\hline \multirow{2}{*}{ Sex } & Male & $310(74.7)$ & $90(21.7)$ & $15(3.6)$ & $P=0.47,1.14(0.80-1.63)$ & $\mathrm{P}=0.58,1.25(0.55-2.83)$ \\
\hline & Female & $259(77.3)$ & $66(19.7)$ & $10(3.0)$ & \multicolumn{2}{|c|}{ Referent } \\
\hline \multirow{2}{*}{ Liquor Amount } & Abnormal & $60(71.4)$ & $21(25.0)$ & $3(3.6)$ & $\mathrm{P}=0.30,1.32(0.76-2.23)$ & $\mathrm{P}=0.81,1.15(0.33-3.98)$ \\
\hline & Normal & $509(76.4)$ & $135(20.3)$ & $22(3.3)$ & \multicolumn{2}{|c|}{ Referent } \\
\hline \multirow{2}{*}{ Parity } & Primi-Para & $233(68.1)$ & $93(27.2)$ & $16(4.7)$ & $\mathrm{P}<0.001,2.12(1.48-3.05)$ & $\mathrm{P}=0.02,2.56(1.11-5.90)$ \\
\hline & Multi-Para & $336(82.4)$ & $63(15.4)$ & $9(2.2)$ & \multicolumn{2}{|c|}{ Referent } \\
\hline \multirow{2}{*}{ Gestational Age, (weeks) } & $<36$ & $37(38.9)$ & $48(50.5)$ & $10(10.5)$ & $\mathrm{P}<0.001,6.40(3.96-10.2)$ & $\mathrm{P}<0.001,9.56(4.03-22.80)$ \\
\hline & $\geq 37$ & $532(81.2)$ & $108(16.5)$ & $15(2.3)$ & \multicolumn{2}{|c|}{ Referent } \\
\hline \multirow{2}{*}{ Presentation } & Non-Cephalic & $119(73.0)$ & $36(22.1)$ & $8(4.9)$ & $\mathrm{P}=0.55,1.13(0.74-1.73)$ & $\mathrm{P}=0.18,1.77(0.75-4.22)$ \\
\hline & Cephalic & $450(76.7)$ & $120(20.4)$ & $17(2.9)$ & \multicolumn{2}{|c|}{ Referent } \\
\hline \multirow{2}{*}{ Birth Weight, (grams) } & $<2500.0$ & $151(65.4)$ & $69(29.9)$ & $11(4.7)$ & $\mathrm{P}<0.001,2.12(1.47-3.05)$ & $\mathrm{P}=0.06,2.10(0.93-4.72)$ \\
\hline & $2500+$ & $417(80.5)$ & $87(16.9)$ & $14(2.7)$ & \multicolumn{2}{|c|}{ Referent } \\
\hline \multirow{2}{*}{ Apgar score @ 10 min } & $<7.0$ & $3(17.6)$ & $6(35.3)$ & $8(47.1)$ & $\mathrm{P}<0.001,44.92(13.50-149.50)$ & $\mathrm{P}<0.001597 .44(138.83-2570.96)$ \\
\hline & $\geq 7.0+$ & $566(77.2)$ & $150(20.5)$ & $17(2.3)$ & \multicolumn{2}{|c|}{ Referent } \\
\hline \multirow{2}{*}{ Type of CS } & Emergency & $322(68.4)$ & $125(26.5)$ & $24(5.1)$ & $\mathrm{P}<0.0013 .09(2.10-4.74)$ & $\mathrm{P}<0.00118 .4(2.47-137.02)$ \\
\hline & Elective & $247(88.5)$ & $31(11.1)$ & $1(0.4)$ & \multicolumn{2}{|c|}{ Referent } \\
\hline
\end{tabular}

Table 3. Multinominal Regression Analysis for Neonatal Admission and Early Neonatal Death

\begin{tabular}{|c|c|c|c|c|c|c|c|c|c|}
\hline \multirow{2}{*}{\multicolumn{2}{|c|}{$\frac{\text { Neontal Outcome }}{\text { Variables }}$}} & \multicolumn{4}{|c|}{ NICU Admissions } & \multicolumn{4}{|c|}{ NICU Admissions And Early Neonatal Death } \\
\hline & & \multirow[t]{2}{*}{ Pvalue } & \multirow{2}{*}{$\begin{array}{l}\text { Adjusted } \\
\text { OR }\end{array}$} & \multicolumn{2}{|c|}{ 95\% Confidence Interval } & \multirow[t]{2}{*}{ Pvalue } & \multirow{2}{*}{$\begin{array}{l}\text { Adjusted } \\
\text { OR }\end{array}$} & \multicolumn{2}{|c|}{ 95\% Confidence Interval } \\
\hline & & & & Lower & Upper & & & Lower & Upper \\
\hline \multirow{2}{*}{ Type of CS } & Emergency & $<0.001$ & 2.551 & 1.579 & 4.120 & 0.014 & 13.348 & 1.691 & 105.379 \\
\hline & Elective & . & . & . & . & . & . & . & . \\
\hline \multirow{2}{*}{ Parity } & Primi para & 0.049 & 1.503 & 1.003 & 2.252 & 0.212 & 1.844 & 0.706 & 4.817 \\
\hline & Multi para & . & . & . & . & . & . & . & . \\
\hline \multirow{2}{*}{ Presentation } & Non-cephalic & 0.915 & 0.973 & 0.592 & 1.600 & 0.152 & 0.467 & 0.164 & 1.323 \\
\hline & Cephalic & . & . & . & . & . & . & . & . \\
\hline \multirow{2}{*}{ Liquor Amount } & Abnormal & 0.607 & 1.165 & 0.650 & 2.088 & 0.710 & 0.767 & 0.191 & 3.091 \\
\hline & Normal & & & & & & & & \\
\hline \multirow{2}{*}{$\begin{array}{l}\text { Birth Weight, } \\
\text { (grams) }\end{array}$} & $<\mathbf{2 5 0 0}$ & 0.186 & 1.337 & 0.869 & 2.055 & 0.353 & 0.596 & 0.199 & 1.780 \\
\hline & $\geq \mathbf{2 5 0 0}$ & . & . & . & . & . & . & . & . \\
\hline \multirow{2}{*}{ Maturity, (weeks) } & $<37$ & $<0.001$ & 5.116 & 3.003 & 8.855 & $<0.001$ & 10.075 & 3.332 & 30.468 \\
\hline & $\geq 37$ & & & & & & & & \\
\hline \multirow{2}{*}{$\begin{array}{l}\text { Apgar score @ } 10 \\
\text { min }\end{array}$} & $<7$ & 0.02 & 5.523 & 1.292 & 23.605 & $<0.001$ & 79.656 & 16.632 & 381.491 \\
\hline & $\geq 7$ & . & . & . & . & . & . & . & . \\
\hline
\end{tabular}

Abbreviation: CS, cesarean section.

agement following delivery especially for children who are premature and LBW, which have a higher risk of mortality.

This study also has certain limitations. Babies deliv- ered vaginally were not included in the study because of which comparison in morbidity and mortality with normal delivery could not be done. Also, antenatal follow up 
data could be obtained from very few mothers, so it could not be included in analysis.

\subsection{Conclusion}

CSs rates are increasing throughout the world including developed and developing countries and it is associated with an increase in neonatal mortality and morbidity if $\mathrm{CS}$ rates are $>10 \%$. We have observed higher morbidity and mortality of babies born by emergency CS compared to elective CS. The mortality and morbidity rates can be decreased by thorough and regular antenatal checkups and early referrals so that emergency CS can be converted to elective CS by early recognition. In addition, all emergency CS should be attended by pediatricians with full preparation and anticipation of higher mortality especially in babies born by emergency CS, preterm babies and babies having low Apgar scores.

\section{References}

1. WHO . Working Definitions South-East Asia Region: South East Asia Regional Neonatal - Perinatal Database [Internet], World Health Organization; 2016. Available from: http://www.NBwhocc.org/pdf/ database.pdf.

2. Dobson R. Caesarean section rate in England and Wales hits 21. BMJ. 2001;323(7319):951. [PubMed: 11679375].

3. Vogel JP, Betran AP, Vindevoghel N, Souza JP, Torloni MR, Zhang J, et al. Use of the Robson classification to assess caesarean section trends in 21 countries: a secondary analysis of two WHO multicountry surveys. Lancet Glob Health. 2015;3(5):e260-70. doi: 10.1016/S2214109X(15)70094-X. [PubMed: 25866355].

4. Villar J, Carroli G, Zavaleta N, Donner A, Wojdyla D, Faundes A, et al. Maternal and neonatal individual risks and benefits associated with caesarean delivery: multicentre prospective study. BMJ. 2007;335(7628):1025. doi:10.1136/bmj.39363.706956.55. [PubMed: 17977819].
5. Ballard JL, Khoury JC, Wedig K, Wang L, Eilers-Walsman BL, Lipp R. New Ballard Score, expanded to include extremely premature infants.J Pediatr. 1991;119(3):417-23. [PubMed: 1880657].

6. Carter BS, Haverkamp AD, Merenstein GB. The definition of acute perinatal asphyxia. Clin Perinatol. 1993;20(2):287-304. [PubMed: 8358952].

7. Appropriate technology for birth. Lancet. 1985;2(8452):436-7. [PubMed: 2863457].

8. Liston FA, Allen VM, O'Connell CM, Jangaard KA. Neonatal outcomes with caesarean delivery at term. Arch Dis Child Fetal Neonatal Ed. 2008;93(3):F176-82. doi: 10.1136/adc.2006.112565. [PubMed: 17942582].

9. Ye J, Betran AP, Guerrero Vela M, Souza JP, Zhang J. Searching for the optimal rate of medically necessary cesarean delivery. Birth. 2014;41(3):237-44. doi: 10.1111/birt.12104. [PubMed: 24720614].

10. Mehta A, Apers L, Verstraelen H, Temmerman M. Trends in caesarean section rates at a maternity hospital in Mumbai, India. J Health Popul Nutr. 2001;19(4):306-12. [PubMed: 11855353].

11. Mukherjee SN. Rising CS rate. J Obstet Gynecol India. 2006;56(4):298300.

12. Bhasin SK, Rajoura OP, Sharma AK, Metha M, Gupta N, Kumar S, et al. A high prevalence of caesarean section rate in East Delhi. Indian J Community Med. 2007;32(3):222. doi:10.4103/0970-0218.36837.

13. Glavind J, Kindberg SF, Uldbjerg N, Khalil M, Moller AM, Mortensen BB, et al. Elective caesarean section at 38 weeks versus 39 weeks: neonatal and maternal outcomes in a randomised controlled trial. BJOG. 2013;120(9):1123-32. doi:10.1111/1471-0528.12278. [PubMed: 23682628].

14. Lumbiganon P, Laopaiboon M, Gulmezoglu AM, Souza JP, Taneepanichskul S, Ruyan P, et al. Method of delivery and pregnancy outcomes in Asia: the WHO global survey on maternal and perinatal health 2007-08. Lancet. 2010;375(9713):490-9. doi: 10.1016/S01406736(09)61870-5. [PubMed: 20071021].

15. Daniel S, Viswanathan M, Simi BN, Nazeema A. Comparison of Fetal Outcomes of Emergency and Elective Caesarean Sections in a Teaching Hospital in Kerala. Academic Medical J India. 2014;2(1):32-6.

16. Berlit S, Welzel G, Tuschy B, Nickol J, Hornemann A, Sutterlin M, et al. Emergency caesarean section: risk factors for adverse neonatal outcome. Arch Gynecol Obstet. 2013;287(5):901-5. doi:10.1007/s00404-0122679-6. [PubMed: 23241729].

17. Shah A, Fawole B, M'Imunya J M, Amokrane F, Nafiou I, Wolomby JJ, et al. Cesarean delivery outcomes from the WHO global survey on maternal and perinatal health in Africa. Int I Gynaecol Obstet 2009;107(3):191-7. doi: 10.1016/j.ijgo.2009.08.013. [PubMed: 19782977]. 